\title{
Comparison of Frequency of FEV1 in Asymptomatic Smoker and Nonsmoker Doctors
}

\author{
Asim Shaukat, Hassan Bukhari and Adnan Maqsood \\ Department of Radiology, Punjab Medical College, Allied Hospital Faisalabad, Faisalabad 38000, Pakistan
}

\begin{abstract}
OBJECTIVE: To determine the role frequency of decreased Forced expiratory volume in 1 second (FEV1) in between asymptomatic smoker and non smoker doctors. SETTING: Allied Hospital and District Head Quarter Hospital Faisalabad. STUDY DESIGN: Descriptive case series. SAMPLE SIZE: 350. STUDY DURATION: Six month: June 1, 2014 to November $30,2014$. SAMPLING TECHNIQUE: Non-probability consecutive sampling. STUDY DESIGN: Descriptive case series. METHODS: A total of 350 doctors meeting the inclusion criteria were selected for this study. Outcome variable was decreased FEV1 in both smoker and non smoker doctors. RESULTS: The mean age of the patients was $34.9 \pm 5.9$ years. The mean percentage of FEV1 predicted of the patients was $89.6 \pm 8.3$ percent. There were $35(10.0 \%)$ patients had decreased FEV1 and $315(90.0 \%)$ patients had not decreased FEV1. There were $33(94.3 \%)$ patients smoker in which FEV1 decreased and 2 (5.7\%) patients non-smoker in which FEV1 decreased. CONCLUSION: It is concluded from the results of this study that frequency of decreased FEV1 was found in doctors, but it is found more in asymptomatic smokers than in non smokers. As in our study decreased FEV1 was found in $94.3 \%$ smokers and $5.7 \%$ in non smokers.
\end{abstract}

Key words: Smoking, FEV1, asymptomatic smoker, non smoker, decreased FEV1.

\section{Introduction}

Tobacco caused 100 million deaths in the 20th century. If current trends continue, it will cause up to one billion deaths in the 21 st century. Unchecked, tobacco related deaths will increase to more than eight million per year by 2030 . More than $80 \%$ of those deaths will be in low and middle income countries as $80 \%$ of the more than one billion smokers worldwide live in low and middle income countries like Pakistan [1]. It represents the most significant risk factor for chronic obstructive pulmonary disease (COPD) and relates to both amount and duration of smoking. It is unusual to develop COPD with less than ten pack years [2]. Physicians and surgeons should be more proactive in tobacco control but cigarette smoking is on rise in doctor's community. Symptoms of lung diseases secondary to smoking appear late so doctors are indifferent to hazards of smoking [3].

Corresponding author: Hassan Bukhari, FCPS (Fellowship College of Physician and Surgeons), senior registrar, research field: chest.
Spirometry can be helpful in determining effects of smoking on ventilatory functions and reduced forced expiratory volume in one second (FEV1) is more suitable utility in assessing baseline risk of COPD, lung cancer, coronary artery disease and stroke, collectively accounting for $70 \%-80 \%$ of premature death in smokers. Reduced FEV1 identifies undiagnosed COPD, has comparable utility to that of serum cholesterol in assessing cardiovascular risk and defines those smokers at greatest risk of lung cancer. As such, reduced FEV1 should be considered a marker that identifies smokers at greatest need of medical intervention. Smoking cessation has been shown to attenuate FEV1 decline and, if achieved before the age of 45-50 years, may not only preserve FEV1 within normal values but substantially reduce cardio respiratory complications of smoking [4].

In a study done in Karachi to determine reference values of FEV1 in Pakistani population, 504 subjects with age 15 to 65 years were evaluated and FEV1 comes out to be $2.86 \pm 0.71$ in non smoker urban 
population on average which has to be calibrated with height, weight and age of subjects. For a male of 40 years age, $175 \mathrm{~cm}$ height FEV1 was 3.01 liter [5].

The GOLD guidelines can be used to interpret the results of FEV1. It proposes four stages of COPD based on Spirometry FEV1 $80 \%$ predicted (Stage 1 Mild), FEV1 of $50 \%-80 \%$ predicted (Stage 2 Moderate), FEV1 of $30 \%-50 \%$ predicted (Stage 3 Severe), and FEVI $30 \%$ predicted or FEV1 50\% predicted plus chronic respiratory failure (Stage 4 Very Severe) [6]. The frequency of decreased FEV1 is $8.5 \%$ out of which $94.11 \%$ were smokers and $5.8 \%$ were non smokers [7].

As stated, earlier detection of airflow obstruction and smoking cessation may result in significant health gain. There is no local study available in last five years which addressed this problem of doctor's community and provide any convincing evidence to launch some screening and preventive program for cigarette smoking.

\section{Material and Methods}

350 doctors meeting the following inclusion criteria from Allied Hospital and DHQ Hospital Faisalabad were explained the purpose of research and informed consent was taken.

\subsection{Inclusion Criteria}

(1) Male doctors.

(2) Age 25 years to 45 years.

(3) Both smokers and non smokers.

\subsection{Exclusion Criteria}

(1) History of asthma, COPD, TB and interstitial lung diseases.

(2) History of taking any regular medication.

The researcher himself was complete the attached proforma to reduce inter observer bias. Forced expiratory volume in first second (FEV1) was measured by Spirolab II spirometer. Weight was measured by calibrated weight scale in light clothing at same interval of time daily (9 to 10 a.m.). Height was measured by stadiometer bare footed and standing erect to nearest contimeter. Predicted values depending upon age, height, weight and race was measured by spirometer software. Our outcome variable was decreased FEV1 in both smoker and non smoker doctors.

SPSS version 17 was used for data analysis. Descriptive statistics was calculated for all quantitative variables like height, weight and FEV1 (both recorded and predicted) as mean and standard deviation and qualitative variables like decrease in FEV1 in smokers and non smokers as percentages and frequencies. Chi square test was used for the comparison of decreased FEV1 among smoker and non smoker doctors. The $P$-value less than 0.05 was taken as significant. Effect modifier like age, weight, height, and pack years were controlled by stratification. Post stratification applying Chi square test.

\section{Results}

The mean age of the patients was $34.9 \pm 5.9$ years. There were $112(32 \%)$ patients in the age range of 25-30 years, $80(22.9 \%)$ patients in the age range of 31-35 years, $80(22.9 \%)$ patients in the age range of $36-40$ years and $78(22.7 \%)$ patients in the age range of 41-45 years (Table 1 ).

The mean height of the patients was $169.9 \pm 9.3 \mathrm{~cm}$. There were $72(20.6 \%)$ patients in the height range of $150-160 \mathrm{~cm}, 113$ (32.3\%) patients in the height range of 161-170 cm, 99 (28.3\%) patients in the height range of 171-180 cm and $78(22.2 \%)$ patients in the height range of 181-190 cm (Table 2).

The mean weight of the patients was $66.7 \pm 14.0 \mathrm{~kg}$. There were $176(50.3 \%)$ patients in the weight range of $50-60 \mathrm{~kg}, 57(16.3 \%)$ patients in the weight range of $61-70 \mathrm{~kg}, 36(10.3 \%)$ patients in the weight range of $71-80 \mathrm{~kg}, 54(15.4 \%)$ patients in the weight range of $81-90 \mathrm{~kg}$ and $27(7.7 \%)$ patients in the weight range of 91-100 kg (Table 3). 
Table 1 Distribution of patients by age $(n=350)$.

\begin{tabular}{lll}
\hline Age (Years) & No. of patients & Percentage \\
\hline $25-30$ & 112 & 32.0 \\
$31-35$ & 80 & 22.9 \\
$36-40$ & 80 & 22.9 \\
$41-45$ & 78 & 22.2 \\
Mean \pm SD & $34.9 \pm 5.9$ & \\
\hline
\end{tabular}

Table 2 Distribution of patients by height $(n=350)$.

\begin{tabular}{lll}
\hline Height $(\mathrm{cm})$ & No. of patients & Percentage \\
\hline $150-160$ & 72 & 20.6 \\
$161-170$ & 113 & 32.3 \\
$171-180$ & 99 & 28.3 \\
$181-190$ & 66 & 18.8 \\
Mean \pm SD & $169.9 \pm 9.3$ & \\
\hline
\end{tabular}

Table 3 Distribution of patients by weight $(n=350)$.

\begin{tabular}{lll}
\hline Weight $(\mathrm{kg})$ & No. of patients & Percentage \\
\hline $50-60$ & 176 & 50.3 \\
$61-70$ & 57 & 16.3 \\
$71-80$ & 36 & 10.3 \\
$81-90$ & 54 & 15.4 \\
$91-100$ & 27 & 7.7 \\
Mean \pm SD & $66.7 \pm 14.0$ & \\
\hline
\end{tabular}

In our study, 250 (71.4\%) patients were smoker and $100(28.6 \%)$ patients were non-smokers (Table 4$)$. The mean pack year of the patients was $10.2 \pm 7.1$. There were $100(28.6 \%)$ patients having 0 pack year (non smoker), 178 (50.8\%) patients were 10-15 pack year, $56(16.0 \%)$ patients were 16-20 pack year and $16(4.6 \%)$ patients were in the 21-25 pack year (Table 5).

The mean FEV1 predicted of the patients was $4.5 \pm$ 0.3 litre. There were $32(9.1 \%)$ patients in the FEV1 predicted range of 3.5-4.0 litre, 180 (51.4\%) patients in the FEV1 predicted range of 4.1-4.5 litre, 122 (35.2\%) patients in the FEV1 predicted range of 4.6-5.0 litre and $15(4.3 \%)$ patients in the FEV1 predicted range of 5.1-5.5 litre (Table 6).

The mean FEV1 recorded of the patients was $4.0 \pm$ 0.3 litre. There were 59 (16.9\%) patients in the FEV1 recorded range of 3.1-3.5 litre, 127 (36.3\%) patients in the FEV1 recorded range of 3.6-4.0 litre, 102 (29.1\%) patients in the FEV1 recorded range of 4.1-4.5 litre, 50 (14.3\%) patients in the FEV1 recorded range of 4.6-5.0 litre and 12 (3.4\%) patients in the FEV1 recorded range of 5.1-5.5 litre (Table 7).

The mean percentage of FEV1 predicted of the patients was $89.6 \pm 8.3$ percent. There were $35(10.0 \%)$ patients in the FEV1 predicted range of $70 \%-80 \%, 159$ (45.4\%) patients in the FEV1 predicted range of $81 \%-90 \%, 124$ (35.4\%) patients in the FEV1 predicted range of $91 \%-100 \%$ and $30(8.6 \%)$ patients in the range of $101 \%-110 \%$ (Table 8 ).

In the distribution of patients by decreased FEV1, 35 (10.0\%) patients had decreased FEV1 and 315 (90.0\%) patients had not decreased FEV1 (Table 9).

In the distribution of patients by decreased FEV1 between smokers and non-smokers, there were 33 (94.3\%) smoker in which FEV1 decreased and 2 (5.7\%) non-smoker in which FEV1 decreased with $P$ value of 0.001 (Table 10).

The stratification of age with FEV1 decreased between smokers and non smokers was described in Table 11. The stratification of height with FEV1 decreased between smokers and non smokers was described in Table 12. The stratification of weight with FEV1 decreased between smokers and non smokers was

Table 4 Distribution of patients by smoker/non smoker ( $n$ = 350).

\begin{tabular}{lll}
\hline Smoker/non smoker & No. of patients & Percentage \\
\hline Smoker & 250 & 71.4 \\
Non smoker & 100 & 28.6 \\
Total & 350 & 100.0 \\
\hline
\end{tabular}

Table 5 Distribution of patients by pack year $(n=350)$.

\begin{tabular}{lll}
\hline Pack year & No. of patients & Percentage \\
\hline 0 & 100 & 28.6 \\
$10-15$ & 178 & 50.8 \\
$16-20$ & 56 & 16.0 \\
$21-25$ & 16 & 4.6 \\
Mean \pm SD & $10.2 \pm 7.1$ & \\
\hline
\end{tabular}

Table 6 Distribution of patients by FEV1 predicted $(n=$ 350).

\begin{tabular}{lll}
\hline FEV1 predicted (Litre) & No. of patients & Percentage \\
\hline $3.5-4.0$ & 32 & 9.1 \\
$4.1-4.5$ & 180 & 51.4 \\
$4.6-5.0$ & 123 & 35.2 \\
$5.1-5.0$ & 15 & 4.3 \\
Mean \pm SD & $4.5 \pm 0.3$ & \\
\hline
\end{tabular}


Table 7 Distribution of patients by FEV1 recorded $(n=$ 350).

\begin{tabular}{lll}
\hline FEV1 recorded (Litre) & No. of patients & Percentage \\
\hline $3.1-3.5$ & 59 & 16.9 \\
$3.6-4.0$ & 127 & 36.3 \\
$4.1-4.5$ & 102 & 29.1 \\
$4.6-5.0$ & 50 & 14.3 \\
$5.1-5.5$ & 12 & 3.4 \\
Mean \pm SD & $4.0 \pm 0.3$ & \\
\hline
\end{tabular}

Table 8 Distribution of patients by percentage of predicted FEV1 $(n=350)$.

\begin{tabular}{lll}
\hline $\begin{array}{l}\text { Percentage of predicted } \\
\text { FEV1 }(\%)\end{array}$ & No. of patients & Percentage \\
\hline $70-80$ & 35 & 10.0 \\
$81-90$ & 159 & 45.4 \\
$91-100$ & 124 & 35.4 \\
$101-110$ & 30 & 8.6 \\
Mean \pm SD & $89.6 \pm 8.3$ & \\
\hline
\end{tabular}

Table 9 Distribution of patients by decreased FEV1 $(n=$ 350).

\begin{tabular}{lll}
\hline Decreased FEV1 & No. of patients & Percentage \\
\hline Yes & 35 & 10.0 \\
No & 315 & 90.0 \\
Total & 350 & 100.0 \\
\hline
\end{tabular}

Table 10 Comparison of FEV1 decreased between smokers and non smokers $(n=35)$.

\begin{tabular}{lll}
\hline FEV1 decreased & No. of patients & Percentage \\
\hline Smokers & 33 & 94.3 \\
Non smokers & 2 & 5.7 \\
Total & 35 & 100.0 \\
\hline
\end{tabular}

$\chi^{2}: 9.96 ;$ df: $1 ; P: 0.001$.

Table 11 Stratification of age with FEV1 decreased between smokers and non smokers $(n=35)$.

\begin{tabular}{llll}
\hline Age & Smokers & Non-smokers & Total \\
\hline $25-30$ & 17 & 0 & 17 \\
$31-35$ & 8 & 0 & 8 \\
$36-40$ & 5 & 0 & 5 \\
$41-45$ & 3 & 2 & 5 \\
Total & 33 & 2 & 35 \\
\hline
\end{tabular}

$\chi^{2}: 27.8$; df: $19 ; P: 0.04$.

Table 12 Stratification of height with FEV1 decreased between smokers and non smokers $(n=35)$.

\begin{tabular}{llll}
\hline Height $(\mathrm{cm})$ & Smokers & Non-smokers & Total \\
\hline $150-160$ & 1 & 1 & 2 \\
$161-170$ & 15 & 1 & 16 \\
$171-180$ & 15 & 0 & 15 \\
$181-190$ & 2 & 0 & 2 \\
Total & 33 & 2 & 35 \\
\hline
\end{tabular}

$\chi^{2}: 12.4$; df: $30 ; P: 0.03$.
Table 13 Stratification of weight with FEV1 decreased between smokers and non smokers $(n=35)$.

\begin{tabular}{llll}
\hline Weight $(\mathrm{kg})$ & Smokers & Non-smokers & Total \\
\hline $50-60$ & 13 & 0 & 13 \\
$61-70$ & 3 & 2 & 5 \\
$71-80$ & 6 & 0 & 6 \\
$81-90$ & 7 & 0 & 7 \\
$91-100$ & 4 & 0 & 4 \\
Total & 33 & 2 & 35 \\
\hline
\end{tabular}

$\chi^{2}: 20.4$; df: $24 ; P: 0.02$.

Table 14 Stratification of pack year with FEV1 decreased between smokers and non smokers $(n=35)$.

\begin{tabular}{llll}
\hline Pack year & Smokers & Non-smokers & Total \\
\hline 0 & 0 & 2 & 2 \\
$10-15$ & 19 & 0 & 19 \\
$16-20$ & 12 & 0 & 12 \\
$21-25$ & 2 & 0 & 2 \\
Total & 33 & 2 & 35 \\
\hline
\end{tabular}

$\chi^{2}: 315$; df: $13 ; P: 0.001$.

described in Table 13. The stratification of pack year with FEV1 decreased between smokers and non smokers was described in Table 14.

\section{Discussion}

Smoking is a malicious curse of world today. In Pakistan, the highest prevalence of cigarette smoking among males was seen in the age group 24-44 years, whereas in women it is not known.

Smoking related diseases kill one in ten adults globally. Smoking is the single largest preventable cause of disease and premature death. It is a prime etiologic factor in heart disease, stroke and chronic lung disease. There is mounting evidence of the harmful effect of passive smoking. Smoking causes airway obstruction, chronic expectoration and decline in lung functions. All these effects are directly proportional to number of pack years and there is definite tendency to narrowing of both the larger and smaller airways.

Spirometry can be helpful in determining effects of smoking on ventilatory functions. It is the best method to detect borderline to mild airway obstruction, which occurs early without appearance of any symptoms or 
signs. FEV1 is the most important spirometric variable for assessment of airflow obstruction. Smokers have excessive loss of FEV1 of 7.4-12.6 ml/pack year for males and 4.4-7.2 ml/pack year for females [8].

The prevalence of undetected persistent airflow obstruction in middle-aged smokers is high. Earlier detection of airflow obstruction and smoking cessation may result in significant health gain [9]. Smoking cessation reduces the accelerated rate of decline of FEV1 found in smokers compared to non-smokers [10]. These results can be used to convince people to quit smoking.

Extensive literature is now available on the harmful effects of smoking [11]. Cigarette smoke has diverse effects on lung structure and function. Previous studies of lung function testing in the general population have had mixed results, with some showing no effect and others suggesting that knowledge of an abnormal lung function test doubled the likelihood of quitting smoking, even when no other interventions were applied [12].

It is likely that the reversibility of smoke-induced changes differ between smokers without chronic symptoms, smokers with non-obstructive chronic bronchitis and smokers with COPD. Smoking cessation clearly improves respiratory symptoms and bronchial hyper responsiveness, and prevents excessive decline in lung function in all three groups [13].

In our study, the mean age; mean height; mean weight; mean pack year and mean \%FEV1 of the patients were $34.9 \pm 5.9$ years; $169.9 \pm 9.3 \mathrm{~cm} ; 66.7 \pm$ $14.0 \mathrm{~kg} ; 10.2 \pm 7.1$ pack year and $87.0 \pm 10.7$ percent, respectively. As compared with the study of Khan et al. [7], those are $35.08 \pm 4.73$ years; $170.73 \pm 5.76 \mathrm{~cm}$; $67.59 \pm 0.08 \mathrm{~kg} ; 8.51 \%$ and $93.48 \pm 11.63$ percent, which are comparable with our study. Additionally, the decreased FEV1 was found in $10 \%$ patients. As compared with the study of Khan et al. [7], the decreased FEV1 was found in $8.5 \%$ patients, which is comparable with our study. The decreased FEV1 in smokers was found in $94.3 \%$ patients and $5.7 \%$ in non-smokers. As compared with the study of Khan et al. [7], the decreased FEV1 in smokers was found in $94.1 \%$ patients and $5.9 \%$ in non smokers, which is comparable with our study.

On the above discussion, it is concluded that frequency of decreased FEV1 was found in doctors, but it is found more in asymptomatic smokers than non-smokers.

\section{Conclusion}

It is concluded from the results of this study that frequency of decreased FEV1 was found in doctors, but it is found more in asymptomatic smokers than in non smokers. As in our study, decreased FEV1 was found in $94.3 \%$ smokers and $5.7 \%$ in non smokers.

\section{References}

[1] World Health Organization. 2013. Tobacco World Health Organization Fact Sheet No. 339. Geneva: World Health Organization.

[2] Reid, P. T., and Innes, J. 2010. "Respiratory Diseases.” In Davidson's Principles and Practice of Medicine, 21st ed., edited by Colledge, N. R., Walker, B. R., and Ralston, S. H. Edinburgh: Elsevier, 641-730.

[3] Malik, A. K., Chaudhry, A., Karamat, A., Arif, N., Cheema, M. A., and Rauf, A. 2010. "Cigarette Smoking and Health Care Professionals at Mayo Hospital, Lahore, Pakistan." J. Pak. Med. Assoc. 60 (6): 509-12.

[4] Young, R. P., Hopkins, R., and Eaton, T. E. 2007. "Forced Expiratory Volume in One Second, Not Just a Lung Function Test but a Marker of Premature Death from All Causes." Eur. Respir. J. 30 (4): 616-22.

[5] Memon, M. A., Sandila, M. P., and Ahmed, S. T. 2007. "Spirometric Reference Values in Healthy, Non Smoking, Urban Pakistani Population.” J. Pak. Med. Assoc. 57 (4): 193-5.

[6] Vestho, J., Hurel, S. S., Agusti, A. G., Jones, P. W., Vogelmeier, C., Anzueto, A., Barnes, P. J., Fabbri, L. M., Martinez, F. J., Nishimura, M., Stockley, R. A., Sin, D. D., and Rodriguez-Rosini, R. 2013. "Global Strategy for the Diagnosis, Management and Prevention of Chronic Obstructive Pulmonary Disease. GOLD Executive Summary." Am. J. Respir. Crit. Care. Med. 187: 347-65.

[7] Khan, A., Shabir, K., Ansari, J. K., and Zia, N. 2010. "Comparison of Forced Expiratory Volume in One Second among Asymptomatic Smokers and Non Smokers.” J. Pak. 
Med. Assoc. 60 (3): 209-13.

[8] Longmore, M., Ian, B. Wilkinson, I. B., and Rajagoplan, S. 2004. "Chest Medicine." In Oxford Handbook of Clinical Medicine. 6th ed. New York: Oxford University Press, 189.

[9] Geijer, R. M., Sachs, A. P., Hoes, A. W., Salome, P. L., Lammers, J. W., and Verheij, T. J. 2005. "Prevalence of Undetected Persistent Airflow Obstruction in Male Smokers 40-65 Years Old.” Fam. Pract. 22 (5): 485-9.

[10] Anthonisen, N. R., Connett, J. E., Kiley, J. P., Altose, M. D., Bailey, W. C., Buist A. S., Conway, W. A. Jr., Enright, P. L., Kanner, R. E., and O'Hara, P. 1994. "Effects of Smoking Intervention and the Use of an Inhaled Anticholinergic Bronchodilator on the Rate of Decline of
FEV1. The Lung Health Study." JAMA. 272 (19): 1497-505.

[11] Chhabra, S. K. 1999. "The Rising Menace of Environmental Tobacco Smoke." Indian. J. Chest. Dis. Allied. Sci. 41 (4): 191-4.

[12] Loss, R. W., Hall, W. J., and Speers, D. M. 1979. "Evaluation of Early Airway Disease in Smokers: Cost Effectiveness of Pulmonary Function Testing." Am. J. Med. Sci. 278 (1): 27-37.

[13] Willemse, B. W. M., Postma, D. S., Timens, W., and ten Hacken, N. H. T. 2004. "The Impact of Smoking Cessation on Respiratory Symptoms, Lung Function, Airway Hyperresponsiveness and Inflammation." Eur. Respir. J. 23 (3): 464-76. 